\title{
An Exploratory Study of a Novel Approach to Improve Readiness for a Rural Family Medicine Residency
}

Dwight Smith, MD | Nellie Wirsing, MD | Joyce C. Hollander-Rodriguez, MD | Tracy Bumsted, MD, MPH | Eric Wiser, MD | Jessica Weyler | Lily Cranor, MD | Patricia A. Carney, PhD, MS PRiMER. 2021;5:33.

Published: 10/1/2021 | DOI: 10.22454/PRiMER.2021.234155

\section{Abstract}

Background and Objectives: Transitioning from medical school to residency is challenging, especially in rural training programs where a comprehensive scope of practice is needed to address rural health disparities. Oregon Health \& Science University partnered with Cascades East Family Medicine Residency in Klamath Falls, Oregon to create an integrated fourth-year medical student experience (Oregon Family medicine Integrated Rural Student Training (Oregon FIRST). Participants may then enter this residency to complete their training with the intention to practice in rural underresourced settings.

Methods: In this exploratory study, we conducted key informant interviews with 9 of ten Oregon FIRST participants to determine how Oregon FIRST contributed both to their readiness for residency training and their choice to practice in rural underserved locations. Interviews were conducted between June 10, 2020 and July 8, 2020. We analyzed field notes taken during interviews for emergent themes using classical content analysis.

Results: Emergent themes included logistical ease, relationship development, key curricular elements, and commitment to rural practice. Overwhelmingly, Oregon FIRST participants reported the experience had many challenging and demanding components because they served as subinterns for their entire fourth year of medical school, but this prepared them very well for internship. When asked if they would choose to enroll in Oregon FIRST again, given what they now know about physician training and patient care, all nine $(100 \%)$ said they would.

Conclusions: This study demonstrated that Oregon FIRST students felt better prepared for the rigors of residency and are committed to practicing in rural areas.

\section{Introduction}

Transitioning from medical school to residency is challenging. Medical errors due to lack of preparedness have been reported. ${ }^{1,2}$ Residency programs have used boot camps, preparatory courses, and immersion rotations ${ }^{3-6}$ to ease the transition. Medical schools responsible for preparing learners for residency ${ }^{7}$ are adopting competency-based assessments to improve transitions to residency. ${ }^{8}$ Creating stronger partnerships between 
medical schools and residency programs is another strategy to improve preparedness. ${ }^{9,10}$

Rural health disparities are worsening, and a broader scope of practice is needed. ${ }^{11,12}$ Thach and colleagues ${ }^{13}$ identified five recommendations for rural practice preparation: (1) be intentional about strategies to prepare learners for rural practice; (2) identify and cultivate rural interest; (3) develop confidence and competence to meet rural community needs; (4) teach skills in negotiating dual relationships, leading, and improving community health; and (5) fully engage rural host communities throughout training.

To address these issues, Oregon Health \& Science University (OHSU) and Cascades East Family Medicine Residency (CEFMR) implemented Oregon Family medicine Integrated Rural Student Training (Oregon FIRST). Here we describe the study we conducted to assess participants' experiences and early outcomes of Oregon FIRST using recommendations made by Thach et al. ${ }^{13}$

\section{Methods}

\section{Setting, Development, and Implementation}

CEFMR, administered by OHSU, is an 8-8-8 rural residency program based at Sky Lakes Medical Center in Klamath Falls, Oregon, a rural community of 21,934 people, 80 miles from the nearest tertiary care hospital. ${ }^{14}$ Oregon FIRST involves fourth-year OHSU medical students undertaking a 9-month family medicine subinternship in Klamath Falls (Table 1). After approval by Sky Lakes Medical Center leadership, Oregon FIRST was accepted by OHSU's School of Medicine and enrollment began in 2014.

\section{Medical Student Recruitment/Participation}

OHSU medical students apply to Oregon FIRST during their third year and are selected with the same thoroughness as residency applicants. Applications include a personal statement of interest and goals, curriculum vitae, medical school transcript, grade narrative/Medical Student Performance Evaluation (MSPE) comments, United States Medical Licensing Exam I score, and two faculty letters of recommendation, one from a family physician. Each candidate receives a formal interview similar to residency interviews. Applicants are evaluated based on commitment to full-spectrum rural family medicine, academic achievements, and service activities.

In their fourth year, Oregon FIRST participants apply to CEFMR through Electronic Residency Application Service (ERAS) on the normal timeline, and participate in the National Residency Matching Program (NRMP). Two of CEFMRs eight intern positions are ideally filled with Oregon FIRST participants, though during some years only one student was selected. Though the NRMP offers an exception to its All In Policy ${ }^{15}$ for rural programs, it has not encouraged programs to apply when they can meet their program's stated goals without an exception. ${ }^{16}$ Oregon FIRST emphasizes student safety in their ability to opt out and apply to other programs, while also offering students comfort that the selection process for Oregon FIRST matches the criteria for residency selection to foster confidence they are likely to match.

\section{Experience Evaluation and Data Analyses}

Oregon FIRST is in its sixth year. We conducted key informant interviews with nine of ten participants who completed the experience. Two students participated in each of 2014, 2016, 2017, and 2019, and one student participated in 2015 and 2018. Interviews were conducted between June 10, 2020 and July 8, 2020, and lasted 18-45 minutes (mean=34.3). We collected field notes with a review/validation step at the end of each interview and compiled into a single document for analyses. We used classical content analysis ${ }^{17}$ to identify emergent themes that addressed two research questions: (1) In what ways did Oregon FIRST prepare students for their internship year?, and (2) How did Oregon FIRST affect students' choice to practice in rural underresourced 
settings? We additionally mapped our findings to Thach's recommendations for rural practice preparation. ${ }^{13}$ Additional data were collected from administrative databases, including age, gender, and career status. All study activities were approved by OHSU's Institutional Review Board (IRB \# 21532).

\section{Results}

Participants' average age was 31.1 years $(S D=3.2)$; they were predominantly female (Table 2). Seven were residents, and two were in independent clinical practice. Emergent themes included logistics, relationships, key curricular elements, and commitment to rural practice (Table 3). Overwhelmingly, Oregon FIRST participants perceived receiving a better educational experience to prepare for residency compared to other fourth-year medical students in their cohort. They reported that by serving as subinterns for 9 months, they become more proficient at handling demanding experiences, such as many hours providing care to acutely ill patients, which helped prepare them for internship. When asked if they would choose to participate in Oregon FIRST again, $100 \%$ said they would.

Other outcomes from Oregon FIRST include that 100\% matched at CEFMR, $100 \%$ of graduates achieved board certification in family medicine on their first attempt, one is a chief resident, and two are in independent clinical practice. Both graduates in independent clinical practice are doing full spectrum in- and outpatient and maternity care in rural Oregon. Two Oregon FIRST students for 2019/2020 completed their degree requirements and graduated early. After successfully matching at CEFMR in March, they started residency in April to assist with COVID-19 pandemic care.

\section{Discussion}

This study demonstrated that Oregon FIRST students felt well prepared for the rigors of rural residency training and remained committed to rural practice. Becoming familiar with locations, spaces, and processes of residency created efficiencies and confidence performing the duties of an intern. Relationship development with peers and mentors was valued, as were key curricular elements, such as developing longitudinal relationships with patients seen in continuity clinic, which made it easier to see more patients during internship year. Inpatient rotations exposed them to complex patients, and elective time filled important gaps in knowledge/skills. The vast majority of participants expressed interest in rural practice before undertaking Oregon FIRST and it solidified that this was their best career choice. The two participants who undertook Oregon FIRST solo expressed difficulty associated with not having a medical student peer.

Oregon FIRST findings mapped to the first four of the five recommendations reported by Thach et al. ${ }^{13}$ The only one that did not map was fully engaging rural host communities throughout the training process. Though Oregon FIRST students did interact with host communities to meet Tach's fourth recommendation, we have not figured out how to fully engage continuously during training due to strenuous schedules, but this is a future goal. One study that integrated internal medicine residency into the fourth year of medical school found that it increased the number of trainees entering primary care a year earlier while maintaining academic standards. ${ }^{10}$

Limitations of this study include small sample size, single-site study, and limited outcome data because it is too soon to have many graduates in clinical practice. Another potential limitation is social response bias of participants, though to mitigate this, the person conducting interviews (Author P.A.C.) was not known to participants. Future work will address these limitations, as the concept is now part of the California Oregon Medical Partnership to Address Disparities in Rural Education and Health, a partnership between OHSU and the University of California, Davis, where we will be working with 10 residencies located in rural Oregon and rural Northern California. ${ }^{18}$ 


\section{Tables and Figures}

Table 1: Oregon Family Medicine Integrated Rural Student Training (Oregon FIRST) Components

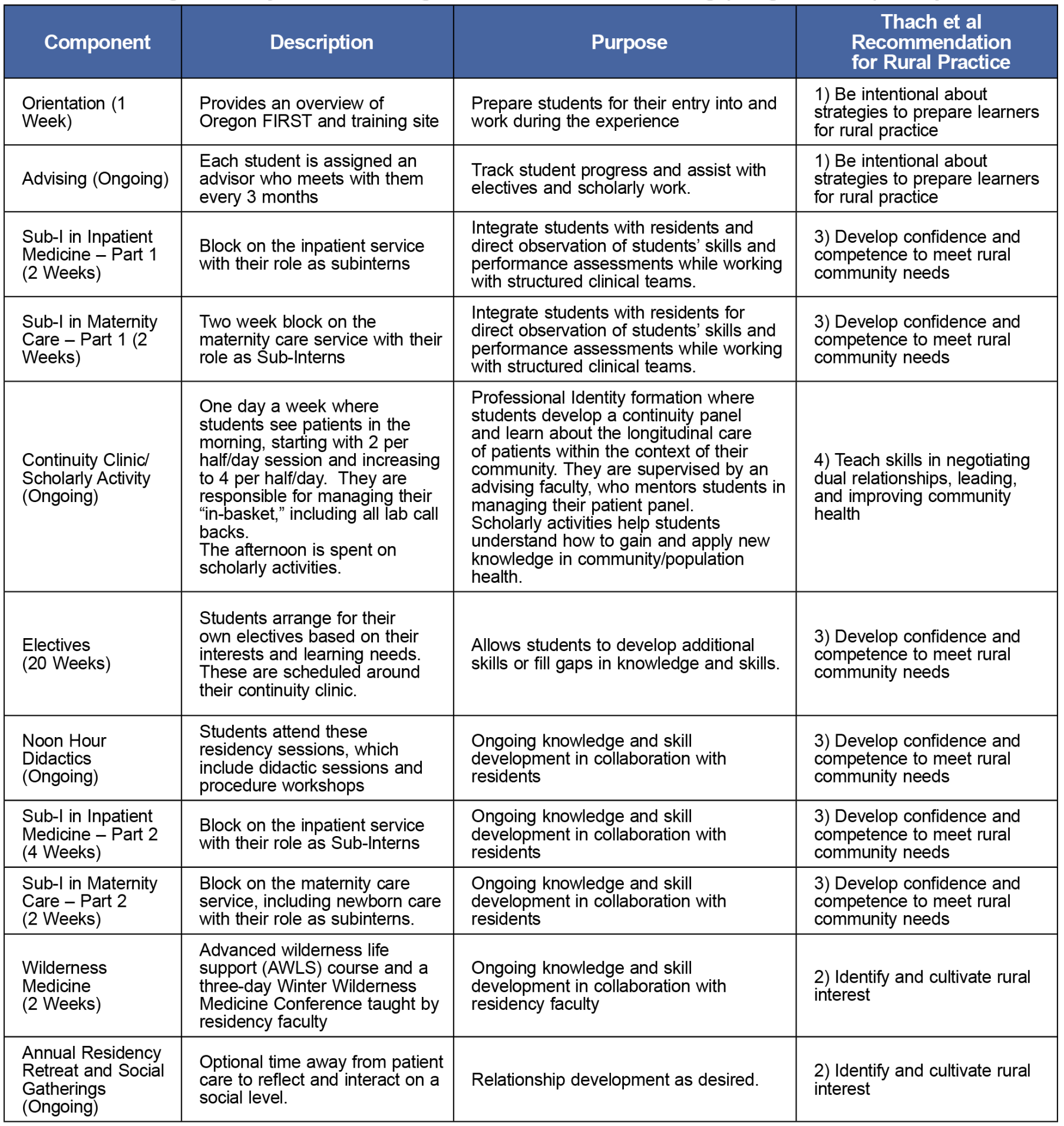


Table 2: Study Participant Characteristics

\begin{tabular}{|l|c|}
\hline \multicolumn{1}{|c|}{ Characteristics } & Values, n=9 \\
\hline Mean Age in Years (SD) ${ }^{+}$ & $\mathbf{3 1 . 1 ( 3 . 2 )}$ \\
Range & $27-37$ \\
\hline Gender Identity & $\mathrm{n}(\%)$ \\
Male & $2(22.2)$ \\
Female & $6(66.7)$ \\
Nonbinary & $1(11.1)$ \\
\hline Career Status & $\mathrm{n}(\%)$ \\
Residents & $7(77.8)$ \\
PGY 1 & $3(33.3)^{*}$ \\
PGY 2 & $1(11.1)$ \\
PGY 3 & $3(33.3)^{* *}$ \\
Independent Practice & $2(22.2)$ \\
Number of years & $1-2$ years \\
\hline
\end{tabular}

† $\mathrm{SD}=$ standard deviation.

* Two posgraduate year-1s were recent medical school graduates who started residency early.

** Two postgraduate year-3 residents were chief residents. 
Table 3: Emergent Themes Regarding Preparedness for Internship Year and Rural Underserved Career Choice

\begin{tabular}{|c|c|c|c|}
\hline $\begin{array}{l}\text { Emergent } \\
\text { Theme }\end{array}$ & Description & Relevant Content Provided by Participants & $\begin{array}{l}\text { Mapped to Thach et } \\
\text { al Recommendation } \\
\text { for Rural Practice }\end{array}$ \\
\hline \multicolumn{4}{|c|}{ In what ways did Oregon FIRST better prepare you for your internship year? } \\
\hline Logistics & $\begin{array}{l}\text { The detailed } \\
\text { coordination of } \\
\text { complex operations } \\
\text { involving many } \\
\text { people, facilities, } \\
\text { locations, spaces } \\
\text { and supplies. }\end{array}$ & $\begin{array}{l}\text { - Oregon FIRST participants reported that knowing the locations, spaces and } \\
\text { processes related to the residency, both in terms of educational and } \\
\text { clinical logistics resulted in greater efficiencies related to training and } \\
\text { patient care. } \\
\text { Exemplars: } \\
\text { - "Got to do rotations, especially hospital medicine where I got to learn how to } \\
\text { be an intern, knew what to expect, got the logistics figured out early and } \\
\text { I could hit the ground running." [Participant \#4] } \\
\text { - "Getting familiar with the system and functioning both in clinic and on the } \\
\text { wards was great." [Participant \#5] }\end{array}$ & $\begin{array}{l}\text { 1) Intentional strategies to } \\
\text { prepare learners for rural } \\
\text { practice }\end{array}$ \\
\hline Relationships & $\begin{array}{l}\text { The connections } \\
\text { or associations } \\
\text { between persons. }\end{array}$ & $\begin{array}{l}\text { - Oregon FIRST participants reported developing strong relationships with } \\
\text { their mentors and their peers, both during their fourth year of medical } \\
\text { school and when they entered residency. } \\
\text { - They often served as valued resources for other interns in their cohort for } \\
\text { logistical assistance and established valued relationships with PGY2 } \\
\text { residents, and with other faculty at Sky Lakes with whom they did both } \\
\text { electives or Sub-ls. } \\
\text { - When fourth-year medical students were enrolled in Oregon FIRST as solo } \\
\text { students, they missed having a peer to interact with to manage the } \\
\text { stress of this fast-paced experience. } \\
\text { Exemplars: } \\
\text { - "Got to meet all the attendings, and care processes and meeting everyone } \\
\text { you will consult with. Establishing these relationships earlier was so } \\
\text { helpful." [Participant \#5] } \\
\text { - "Because I didn't have an Oregon FIRST Peer, sometimes it was hard being } \\
\text { on the wards." [Participant \#1] }\end{array}$ & $\begin{array}{l}\text { 1) Intentional strategies to } \\
\text { prepare learners for rural } \\
\text { practice }\end{array}$ \\
\hline $\begin{array}{l}\text { Key curricular } \\
\text { elements }\end{array}$ & $\begin{array}{l}\text { The goals, needs } \\
\text { analysis, exercises } \\
\text { and activities, } \\
\text { resources, ways } \\
\text { of learning, skills } \\
\text { to be acquired, } \\
\text { and performance } \\
\text { assessment } \\
\text { associated with } \\
\text { Oregon FIRST. } \\
\text { The Key Informant } \\
\text { Interviewer probed } \\
\text { all interviewees on } \\
\text { each Oregon FIRST } \\
\text { curricular element. }\end{array}$ & 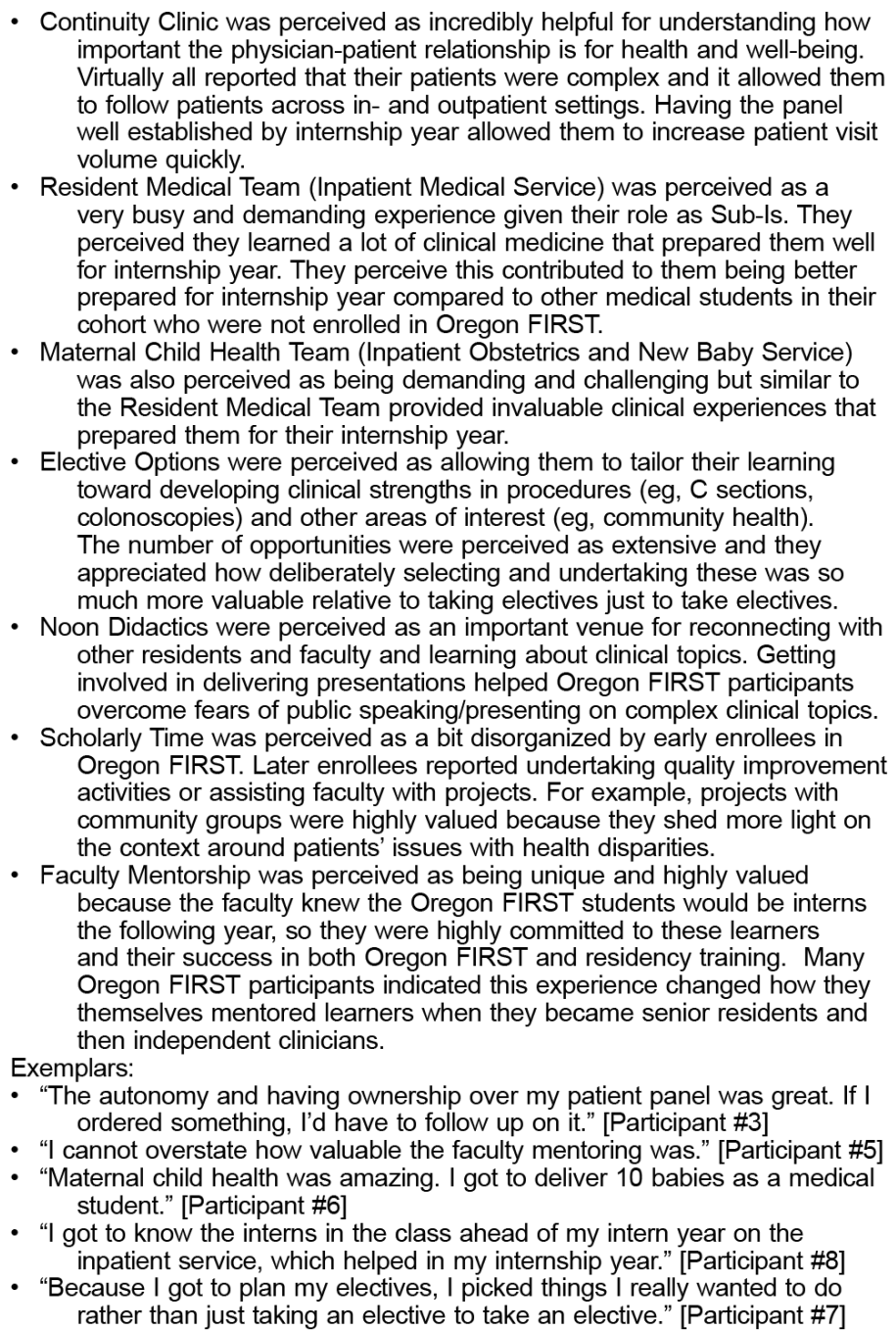 & $\begin{array}{l}\text { 2) Identify and cultivate } \\
\text { rural interest } \\
\text { 3) Develop confidence } \\
\text { and competence to meet } \\
\text { rural community needs } \\
\text { 4) Teach skills in } \\
\text { negotiating dual } \\
\text { relationships, leading, } \\
\text { and improving community } \\
\text { health }\end{array}$ \\
\hline
\end{tabular}


Table 3: Continued

\begin{tabular}{|c|c|c|c|}
\hline $\begin{array}{l}\text { Emergent } \\
\text { Theme }\end{array}$ & Description & Relevant Content Provided by Participants & $\begin{array}{l}\text { Mapped to Thach et } \\
\text { al Recommendation } \\
\text { for Rural Practice }\end{array}$ \\
\hline $\begin{array}{l}\text { Commitment } \\
\text { to rural } \\
\text { practice }\end{array}$ & $\begin{array}{l}\text { State of being } \\
\text { dedicated to } \\
\text { practicing in rural } \\
\text { underresourced } \\
\text { communities. }\end{array}$ & $\begin{array}{l}\text { - Participants reported that the Oregon FIRST experience solidified their } \\
\text { interest in practicing in rural areas. All expressed interest at the start of } \\
\text { the experience, which was an application requirement. However, the vast } \\
\text { majority expressed plans to work in rural underserved areas. Those that } \\
\text { did not, indicated their decision was hampered by external factors, such } \\
\text { as a spouse whose work life required access to metropolitan areas. } \\
\text { Exemplars: } \\
\text { - "I had already decided on rural practice and OR first reaffirmed this choice." } \\
\text { [Participant \#8]. } \\
\text { - "Doing Oregon FIRST reaffirmed that rural practice was the right move for } \\
\text { me." [Participant \#9] }\end{array}$ & $\begin{array}{l}\text { 2) Identify and cultivate } \\
\text { rural interest }\end{array}$ \\
\hline
\end{tabular}

\section{Acknowledgments}

This work was supported by Cascades East Family Medicine Residency Program, Oregon Health \& Science University School of Medicine and Provost's Office, and the California Oregon Medical Partnership to Address Disparities in Rural Education and Health (COMPADRE) as part of the American Medical Association's Reimaging Residency Initiative.

\section{Corresponding Author}

Patricia A. Carney, PhD, MS

Oregon Health and Science University, 3181 SW Sam Jackson Park Rd MC: FM, Portland, OR 97239.

503-494-9049. Fax: 503-494-2746.

carneyp@ohsu.edu

\section{Author Affiliations}

Dwight Smith, MD - Oregon Health \& Science University, Klamath Falls, OR Nellie Wirsing, MD - Oregon Health \& Science University, Klamath Falls, OR Joyce C. Hollander-Rodriguez, MD - Oregon Health \& Science University Department of Family Medicine, Klamath Falls, OR

Tracy Bumsted, MD, MPH - Oregon Health \& Science University, Portland, OR

Eric Wiser, MD - Oregon Health \& Science University, Portland, OR

Jessica Weyler - Oregon Health \& Science University, Portland, OR

Lily Cranor, MD - Oregon Health \& Science University, Klamath Falls, OR

Patricia A. Carney, PhD, MS - Oregon Health \& Science University, Portland, OR

\section{References}

1. Bingham CM, Crampton R. A review of prevocational medical trainee assessment in New South Wales. Med J Aust. 2011;195(7):410-412. doi:10.5694/mja11.10109

2. Kilminster S, Zukas M, Quinton N, Roberts T. Preparedness is not enough: understanding transitions as critically intensive learning periods. Med Educ. 2011;45(10):1006-1015.

doi:10.1111/j.1365-2923.2011.04048.x

3. Minha S, Shefet D, Sagi D, Berkenstadt H, Ziv A. “See One, Sim One Do One” - A national pre-internship boot camp to ensure a safer "Student to Doctor Transition. PLoS One, 2016, 2; 11(3):e0150122. 
4. Lerner V, Higgins EE, Winkel A. Re-boot: simulation elective for medical students as preparation bootcamp for obstetrics and gynecology residency. Cureus. 2018;10(6):e2811. doi:10.7759/cureus.2811

5. Scicluna HA, Grimm MC, Jones PD, Pilotto LS, McNeil HP. Improving the transition from medical school to internship - evaluation of a preparation for internship course. BMC Med Educ. 2014;14(1):23. doi:10.1186/1472-6920-14-23

6. Vairy S, Jamoulle O, Levy A, Carceller A. Transitioning from medical school to residency: evaluation of an innovative immersion rotation for PGY-1 paediatric residents. Paediatr Child Health. 2018;23(2):96-100. doi:10.1093/pch/pxx147

7. The core entrustable professional activities for entering residencies. Association of American Medical Colleges. Accessed April 16, 2020. https://www.aamc.org/what-we-do/mission-areas/medical-education /cbme/core-epas

8. Harris P, Snell L, Talbot M, Harden RM; International CBME Collaborators. Competency-based medical education: implications for undergraduate programs. Med Teach. 2010;32(8):646-650. doi:10.3109/0142159X.2010.500703

9. Chang LL, Grayson MS, Patrick PA, Sivak SL. Incorporating the fourth year of medical school into an internal medicine residency: effect of an accelerated program on performance outcomes and career choice. Teach Learn Med. 2004;16(4):361-364. doi:10.1207/s15328015tlm1604_9

10. Integrated medical school and family medicine residency. Michigan State University. Accessed December 6, 2020. https://chmfamilymedicine.msu.edu/teaching/scholarships/tip/

11. James CV, Moonesinghe R, Wilson-Frederick SM, Hall JE, Penman-Aguilar A, Bouye K. Racial/ethnic health disparities among rural adults - United States. MMWR Surveill Summ. 2017;66(23):1-9. Published. 2012-2015;2017(Nov):17. doi:10.15585/mmwr.ss6623a1

12. Skariah JM, Rasmussen C, Hollander-Rodriguez J, et al. Rural curricular guidelines based on practice scope of recent residency graduates practicing in small communities. Fam Med. 2017;49(8):594-599.

13. Thach SB, Hodge B, Cox M, Parlier-Ahmad AB, Galvin SL. Cultivating Country Doctors: Preparing Learners for Rural Life and Community Leadership. Fam Med. 2018;50(9):685-690. doi:10.22454/FamMed.2018.972692

14. World Population Review: Klamath Falls, Oregon Population 2021. Accessed August 13, 2020. https://worldpopulationreview.com/us-cities/klamath-falls-or-population

15. All In Policy - Main Residency Match. National Residency Match Program. Accessed August 16, 2021. https://www.nrmp.org/all-in-policy/main-residency-match/

16. All In Policy Exception Criteria and Request Form. National Residency Match Program. Accessed August 16, 2021. https://mk0nrmp3oyqui6wqfm.kinstacdn.com/wp-content/uploads/2020/09/ExceptionForm-2020.pdf

17. Bauer MW, Gaskell G. (2000). Classical content analysis: a review. In: Qualitative Researching With Text, Image and Sound. Thousand Oaks, CA: Sage Publications. pgs 132-152. doi:10.4135/9781849209731.n8

18. Reimaging Residency Initiative. American Medical Association. Accessed November 17, 2020. https://www.ama-assn.org/education/improve-gme/ama-reimagining-residencyinitiative?gclid=EAlalQobChMIzJWCjZOK7QIVRRh9Ch2buwV3EAAYASAAEgKOnfD_BwE 